\title{
Bioactivities of Murraya koenigii (Linn.) and Adina cordifolia (Roxb.)
}

\author{
Faiza Tahia ${ }^{1}$, Md. Al Amin Sikder ${ }^{1}$, Mohammad A. Sayeed ${ }^{2}$ and Mohammad A. Rashid \\ ${ }^{1}$ Phytochemical Research Laboratory, Department of Pharmaceutical Chemistry, Faculty of Pharmacy, \\ University of Dhaka, Dhaka-1000, Bangladesh \\ ${ }^{2}$ International Islamic University of Chittagong (IIUC), Chittagong, Bangladesh
}

Received: October 01, 2014; Accepted: December 24, 2014

\begin{abstract}
The present study was designed to evaluate the antioxidant, cytotoxic, thrombolytic, membrane stabilizing and antimicrobial activities of methanol extracts and different organic soluble partitionates of leaves of Murraya koenigii and bark of Adina cordifolia. In the DPPH free radical scavenging assay, the chloroform soluble fraction of methanol extracts of $M$. koenigii and $A$. cordifolia revealed the highest free radical scavenging activity with $\mathrm{IC}_{50}$ values of $6.9 \pm 0.78 \mu \mathrm{g} / \mathrm{ml}$ and $6.83 \pm 0.29 \mu \mathrm{g} / \mathrm{ml}$, while the methanolic crude extract of $M$. koenigii and $A$. cordifolia displayed the highest cytotoxic potential having $\mathrm{LC}_{50}$ values of $1.94 \pm 0.36 \mu \mathrm{g} / \mathrm{ml}$ and $0.88 \pm 0.64$ $\mu \mathrm{g} / \mathrm{ml}$, respectively as compared to standard vincristine sulphate $\left(\mathrm{LC}_{50}\right.$ value of $\left.0.45 \mu \mathrm{g} / \mathrm{ml}\right)$. During assay for thrombolytic activity, the crude extracts of $M$. koenigii and A. cordifolia showed $8.6 \pm 0.48 \%$ and $9.25 \pm 0.84 \%$ clot lysis, respectively. In the membrane stabilizing assay, the methanol extract of $M$. koenigii inhibited $62.80 \pm$ $0.81 \%$ and $21.23 \pm 0.84 \%$ hypotonic solution- and heat-induced haemolysis of RBCs as compared to $72.2 \%$ and $42.2 \%$ inhibition by acetyl salicylic acid $(0.10 \mathrm{mg} / \mathrm{ml})$, respectively. On the other hand, the methanol extract of $A$. cordifolia demonstrated $42.04 \pm 0.57 \%$ and $21.57 \pm 0.22 \%$ inhibition of hypotonic solution- and heat-induced hemolysis, respectively. The extractives of $A$. cordifolia exhibited antibacterial activity with zone of inhibition ranging from 8.0 to $26.0 \mathrm{~mm}$ against the test microorganisms with the highest zone of inhibition $(26.0 \mathrm{~mm})$ against Salmonella Typhi. Although the methanol extract of leaf of $M$. koenigii as well as its pet ether and aqueous soluble fractions demonstrated no antimicrobial activity, the carbon tetrachloride soluble fraction (CTC) revealed moderate antibacterial activity against Staphylococcus aureus $(16.0 \mathrm{~mm})$.
\end{abstract}

Key words: Murraya koenigii, Adina cordifolia, antioxidant, DPPH, cytotoxicity, thrombolysis, membrane stabilization, antibacterial.

\section{Introduction}

According to the World Health Organization (WHO), $80 \%$ of the world's population depends on traditional medicines for their primary healthcare. Plants have been used frequently to treat common diseases in rural areas as western medicines are either too expensive or not available (Adamu et al., 2004). It has been reported that 115 articles were published on the antimicrobial activity of medicinal plants in Pubmed during the period between 1966 and 1994, but in the following decade, between 1995 and 2004, 307 were published (Rios et al., 2005). Drugs derived from unmodified natural products or drugs semisynthetically obtained from natural sources corresponded to $78 \%$ of the new drugs approved by the FDA between 1983 and 1994 (Cragg et al., 1997). The demand for more and more drugs from plant sources is increasing. Hence, there is need to screen medicinal plants for promising biological activities (Chowdhury et al., 2009) in order to discover novel drug candidates.

Murraya koenigii (Linn.) (English name: curry leaf; Bengali name: Choto kamini) belongs to the family, Rutaceae. It is more or less a deciduous unarmed shrub or a small tree up to 6 meters in height and widely distributed throughout Bangladesh. Various parts of M. koenigii are used in the treatment of diabetes, skin eruptions, poisonous bites, febrifuge and dysentery (Chowdhury et al., 2008). Previous phytochemical investigations of $M$. koenigii led to the isolation of alkaloids like murryanine, murrayafoline, koenidine and different coumarins, flavonoids etc (Bakar et al., 2007). It was found to possess anthelmintic, anti-inflammatory and hypoglecemic activities (Handral et al., 2012). 
Adina cordifolia (Roxb.) (Synonym: Haldina cordifolia; Bengali name: Kelikodom) belonging to the family Rubiaceae, is a deciduous tree over $20 \mathrm{~m}$ in height. It is native to East Asia and Southeast Asia and grows in Bangladesh, India, and Thailand. Bark and leaves are used for cholera, cold cough, fever, headache, rheumatism etc. Its bark contains alkaloid like 10-deoxycordifoline indole, and flavonoids like dihydroxy tetra $\mathrm{O}$ methyl flavones (Rokade et al., 2013).

As part of our investigations on medicinal plants of Bangladesh (Kaisar et al., 2011), the crude methanol extracts of leaves of $M$. koenigii and bark of A. cordifolia as well as their organic and aqueous soluble fractions were studied for the antioxidant potential in terms of total phenolic content and free radical scavenging, cytotoxic, thrombolytic, membrane stabilizing and antimicrobial activities for the first time and we, here in, report the results of our preliminary investigations.

\section{Materials and Methods}

Collection of plant materials and extraction: The leaves of M. koenigii and bark of A. cordifolia were collected in April 2013 from Dhaka University campus and Chittagong Hill Tracts, respectively. Voucher specimens for these plants have been maintained in Bangladesh National Herbarium, Dhaka, Bangladesh for future reference.

The collected plant materials were cleaned, sun dried and pulverized. The powdered materials (500 g each) from both the plants were separately soaked in 3.0 liters of methanol at room temperature for 7 days. The extracts were filtered through fresh cotton bed and finally with Whatman filter paper number 1 . The filtrates were concentrated with a rotary evaporator at reduced temperature and pressure. An aliquot (5 g) of each of the concentrated methanol extracts was fractionated by the modified Kupchan partitioning protocol (Van Wagenen et al., 1993) and the resultant partitionates were evaporated to dryness to yield pet-ether (PESF), carbon tetrachloride (CTCSF), chloroform (CSF) and aqueous (AQSF) soluble materials (Table 1). The residues were then stored in a refrigerator until further use.

Total phenolic content: The total phenolic content of the extractives was determined with Folin-Ciocalteau reagent by using the method developed by Harbertson and Spayd (2006).

Table 1. Kupchan partitionates of $M$. koenigii and $A$. cordifolia.

\begin{tabular}{|c|c|c|}
\hline $\begin{array}{l}\text { Crude extract/ } \\
\text { Fractions }\end{array}$ & $\begin{array}{c}\text { M. koenigii } \\
\text { (g) }\end{array}$ & $\begin{array}{c}\text { A. cordifolia } \\
(\mathrm{g})\end{array}$ \\
\hline $\mathrm{ME}$ & 5.00 & 5.00 \\
\hline PESF & 0.65 & 0.55 \\
\hline CTCSF & 0.55 & 0.55 \\
\hline CSF & 0.30 & 0.40 \\
\hline AQSF & 2.50 & 2.30 \\
\hline
\end{tabular}

$\mathrm{ME}=$ Methanolic crude extract; $\mathrm{PESF}=$ Pet-ether soluble fraction; $\mathrm{CTCSF}=$ Carbon tetrachloride soluble fraction; $\mathrm{CSF}=$ Chloroform soluble fraction; $\mathrm{AQSF}=$ Aqueous soluble fraction.

$D P P H$ free radical scavenging assay; Following the method developed by Brand-Williams et al., (1995), the antioxidant activity of the test samples was assessed by evaluating the scavenging activities of the stable 1,1diphenyl-2-picrylhydrazyl (DPPH) free radical by using synthetic antioxidants, butylated hydroxytoluene (BHT) and ascorbic acid as positive controls.

Brine shrimp lethality bioassay: This technique was applied for the determination of general toxic properties of the dimethylsulfoxide (DMSO) solution of plant extractives against Artemia salina in a single day assay (Meyer et al., 1982) by using vincristine sulphate as positive control.

Thrombolytic activity: The method developed by Prasad et al., (2006); Harbertson et al. (2006) was used to determine the thombolytic activity by using streptokinase (SK) as positive control.

Membrane stabilizing activity: The membrane stabilizing activity of the extractives was evaluated by the inhibition of heat- and hypotonic solution-induced haemolysis of human erythrocytes following the method developed by Omale et al. (2008).

Antimicrobial screening: Antimicrobial activity was determined by the disc diffusion method (Bauer et al., 1966).

Statistical analysis: For all bioassays, three replicates of each sample were used for statistical analysis and the values are reported as mean $\pm \mathrm{SD}$. 


\section{Results and Discussion}

The crude methanol extracts of leaves of M. koenigii and bark of A. cordifolia as well as their Kupchan partitionates were evaluated for the total phenolic content, free radical scavenging, cytotoxic, thrombolytic, membrane stabilizing and antimicrobial activities.

The total phenolic content of the extractives of $M$. koenigii was found in the range of 2.86 to $8.94 \mathrm{mg}$ of $\mathrm{GAE} / \mathrm{gm}$ of extractives, with the highest amount of phenolics (8.94 $\pm 0.65 \mathrm{mg})$ being observed in the chloroform soluble fraction. Among the extractives of $A$. cordifolia, the total phenolic content was in the range of
1.57 to $9.41 \mathrm{mg}$ of GAE/gm of extractives. In this case, the maximum phenolic compounds $(9.41 \pm 0.23 \mathrm{mg}$ of GAE/gm of extractives) was observed in the chloroform soluble fraction (Table 2).

In the DPPH free radical scavenging assay, the chloroform soluble fraction of leaves of $M$. koenigii revealed maximum free radical scavenging activity $\left(\mathrm{IC}_{50}=\right.$ $6.9 \pm 0.88 \mu \mathrm{g} / \mathrm{ml}$ ) when compared to ascorbic acid $\left(\mathrm{IC}_{50}=5.80 \pm 0.21 \mu \mathrm{g} / \mathrm{ml}\right)$. Among the test samples of $A$. cordifolia, the chloroform soluble materials demonstrated the highest free radical scavenging activity $\left(\mathrm{IC}_{50}=6.83 \pm\right.$ $0.29 \mu \mathrm{g} / \mathrm{ml}$ ) (Table 2).

Table 2. Total phenolic content, free radical scavenging and cytotoxic activities of $M$. koenigii and $A$. cordifolia.

\begin{tabular}{|c|c|c|c|c|}
\hline Plant & Sample/ Standard & $\begin{array}{c}\text { Total phenolic content } \\
\text { (mg of GAE/gm of } \\
\text { extract) }\end{array}$ & $\begin{array}{c}\text { DPPH Free radical } \\
\text { scavenging activity } \\
\left(\mathrm{IC}_{50} \mu \mathrm{g} / \mathrm{ml}\right) \\
\end{array}$ & $\begin{array}{c}\text { Cytotoxicity }\left(\mathrm{LC}_{50}\right. \\
\mu \mathrm{g} / \mathrm{ml})\end{array}$ \\
\hline \multirow{5}{*}{ M. koenigii } & $\mathrm{ME}$ & $8.16 \pm 0.87$ & $11.2 \pm 0.78$ & $1.94 \pm 0.08$ \\
\hline & PESF & $2.86 \pm 0.09$ & $37.4 \pm 0.25$ & $6.47 \pm 0.19$ \\
\hline & CTCSF & $6.15 \pm 0.27$ & $23.4 \pm 0.14$ & $2.46 \pm 0.54$ \\
\hline & $\mathrm{CSF}$ & $8.94 \pm 0.65$ & $6.90 \pm 0.88$ & $2.77 \pm 0.36$ \\
\hline & AQSF & $7.43 \pm 0.81$ & $15.0 \pm 0.57$ & $6.35 \pm 0.68$ \\
\hline \multirow{8}{*}{ A. cordifolia } & $\mathrm{ME}$ & $6.33 \pm 0.54$ & $11.1 \pm 0.18$ & $0.88 \pm 0.84$ \\
\hline & PESF & $1.57 \pm 0.39$ & $71.3 \pm 0.24$ & $4.15 \pm 0.21$ \\
\hline & CTCSF & $8.18 \pm 0.48$ & $9.20 \pm 0.71$ & $2.77 \pm 0.64$ \\
\hline & $\mathrm{CSF}$ & $9.41 \pm 0.23$ & $6.83 \pm 0.29$ & $5.44 \pm 0.82$ \\
\hline & AQSF & $5.89 \pm 0.68$ & $15.2 \pm 0.74$ & $6.85 \pm 0.05$ \\
\hline & VS & - & - & 0.44 \\
\hline & BHT & - & $27.70 \pm 0.54$ & - \\
\hline & Ascorbic acid & - & $5.40 \pm 0.21$ & - \\
\hline
\end{tabular}

$\mathrm{ME}=$ Methanolic crude extract; $\mathrm{PESF}=$ Pet-ether soluble fraction; $\mathrm{CTCSF}=$ Carbon tetrachloride soluble fraction; $\mathrm{CSF}=\mathrm{Chloroform}$ soluble fraction; $\mathrm{AQSF}=$ Aqueous soluble fraction; $\mathrm{BHT}=$ Butylated hydroxytolune; $\mathrm{VS}=$ Vincristine sulfate.

In the brine shrimp lethality bioassay, the methanol extract of $M$. koenigii displayed the highest cytotoxic potential with $\mathrm{LC}_{50}$ value $1.94 \pm 0.08 \mu \mathrm{g} / \mathrm{ml}$ as compared to $0.45 \mu \mathrm{g} / \mathrm{ml}$ for vincristine sulphate. On the other hand, the crude extract of $A$. cordifolia, revealed the highest cytotoxic potential with $\mathrm{LC}_{50}$ value $0.88 \pm 0.84 \mu \mathrm{g} / \mathrm{ml}$. This suggested the presence of potent bioactive components in the above mentioned extractives (Table 2).

The extractives of M. koenigii and A. cordifolia were assayed for thrombolysis to determine the ability of clot lysis. Addition of $100 \mu \mathrm{l}$ streptokinase (SK), a positive control (30,000 I.U.) to the clots of human blood and subsequent incubation for 90 minutes at $37^{\circ} \mathrm{C}$ showed
$65.88 \%$ lysis of the clot as compared to distilled water showing a negligible lysis of clot (3.74\%). In this study, different extractives of $M$. koenigii and A. cordifolia demonstrated weak clot lysis from $1.67 \%$ to $8.60 \%$ and $1.55 \%$ to $9.25 \%$, respectively (Table 3 ).

The membrane stabilizing activity of the extractives of $M$. koenigii and A. cordifolia was also determined. They significantly protected the lysis of human erythrocyte membrane induced by heat and hypotonic solution, as compared to the standard acetyl salicylic acid. In hypotonic solution- and heat-induced conditions, the methanol extract of $M$. koenigii inhibited $62.8 \pm 0.84 \%$ and $21.23 \pm 0.21 \%$ haemolysis of RBCs as compared to 
$72.2 \pm 0.47 \%$ and $42.2 \pm 0.23 \%$ revealed by acetyl salicylic acid $(0.10 \mathrm{mg} / \mathrm{ml})$, respectively (Table 4$)$.

The extractives of $M$. koenigii and A. cordifolia when screened for antibacterial activity against five gram positive and eight gram negative bacteria at a concentration of $400 \mu \mathrm{g} / \mathrm{disc}$, the test samples of $A$. cordifolia revealed significant inhibitory activity against the test pathogens having zone of inhibition ranging from 8.0-26.0 $\mathrm{mm}$, with the highest inhibition of bacterial growth of the crude extract $(26.0 \mathrm{~mm})$ against Salmonella Typhii (Table-5). On the other hand, the methanolic extract and its pet ether and aqueous soluble fractions of M. koenigii exhibited no antimicrobial activity. However, its carbon tetrachloride (CTC) soluble fraction demonstrated moderate activity against Staphylococcus aureus $(16.0 \mathrm{~mm})$. The inhibitory activity of the extractives was compared with ciprofloxacin as standard.

Table 3. Thrombolytic activity of $M$. koenigii and $A$. cordifolia extractives.

\begin{tabular}{lcc}
\hline \multirow{2}{*}{ Sample } & \multicolumn{2}{c}{ \% clot lysis } \\
\cline { 2 - 3 } & M. koenigii & A. cordifolia \\
\hline ME & $8.60 \pm 0.19$ & $9.25 \pm 0.17$ \\
PESF & $5.31 \pm 0.48$ & $4.70 \pm 0.84$ \\
CTCSF & $5.49 \pm 0.56$ & $7.66 \pm 0.23$ \\
CSF & $1.67 \pm 0.11$ & $2.30 \pm 0.45$ \\
AQSF & $2.20 \pm 0.87$ & $1.55 \pm 0.88$ \\
Blank & \multicolumn{2}{c}{$3.74 \pm 0.55$} \\
SK & \multicolumn{2}{c}{$65.88 \pm 1.08$} \\
\hline
\end{tabular}

SK $=$ Streptokinase (Positive control); Water (negative control)

Table 4. Percentage inhibition of hypotonic solution- and heat- induced hemolysis of erythrocyte membrane by M. koenigii and $A$. cordifolia extractives.

\begin{tabular}{lcccc}
\hline \multirow{2}{*}{ Sample } & \multicolumn{3}{c}{ \% Inhibition of haemolysis } \\
\cline { 2 - 5 } & \multicolumn{2}{c}{ M. koenigii } & A. cordifolia \\
\cline { 2 - 5 } & $\begin{array}{c}\text { Hypnotic solution- } \\
\text { induced }\end{array}$ & Heat-induced & $\begin{array}{c}\text { Hypnotic solution- } \\
\text { induced }\end{array}$ & Heat-induced \\
\hline ME & $62.8 \pm 0.84$ & $21.23 \pm 0.21$ & $42.04 \pm 0.15$ & $21.57 \pm 0.28$ \\
PESF & $54.3 \pm 0.23$ & $7.23 \pm 0.27$ & $21.31 \pm 0.22$ & $18.17 \pm 0.57$ \\
CTCSF & $59.7 \pm 0.26$ & $15.56 \pm 0.43$ & $18.29 \pm 0.42$ & $12.30 \pm 0.39$ \\
CSF & $25.7 \pm 0.84$ & $13.23 \pm 0.81$ & $28.59 \pm 0.74$ & $20.04 \pm 0.37$ \\
AQSF & $57.4 \pm 0.84$ & $8.90 \pm 0.53$ & $40.385 \pm 0.36$ & $15.81 \pm 0.52$ \\
Acetyl salicylic acid & $72.2 \pm 0.47$ & $42.2 \pm 0.23$ & $72.2 \pm 0.47$ & $42.20 \pm 0.23$ \\
\hline
\end{tabular}

Table 5. Antibacterial activity of $\boldsymbol{A}$. cordifolia.

\begin{tabular}{|c|c|c|c|c|c|c|}
\hline \multirow[t]{2}{*}{ Test microorganisms } & \multicolumn{6}{|c|}{ Diameter of zone of inhibition (mm) } \\
\hline & ME & PESF & CTCSF & $\mathrm{CSF}$ & AQSF & Ciprofloxacin \\
\hline \multicolumn{7}{|l|}{ Gram positive bacteria } \\
\hline Bacillus cereus & 20.0 & 18.0 & 22.0 & - & - & 40.0 \\
\hline B. megaterium & 25.0 & 15.0 & - & 12.0 & - & 43.0 \\
\hline B. subtilis & 23.0 & - & 15.0 & - & - & 36.0 \\
\hline Staphylococcus aureus & 16.0 & - & 11.0 & - & - & 37.0 \\
\hline Sarcina lutea & 18.0 & 16.0 & 20.0 & 10.0 & - & 40.0 \\
\hline \multicolumn{7}{|l|}{ Gram negetive bacteria } \\
\hline Escherichia coli & 16.0 & 8.0 & 15.0 & - & - & 40.0 \\
\hline Pseudomonas aeruginosa & 18.0 & - & 11.0 & - & - & 47.0 \\
\hline Salmonella Paratyphi & 21.0 & - & 16.0 & - & - & 35.0 \\
\hline S. Typhi & 26.0 & 12.0 & 11.0 & - & - & 30.0 \\
\hline Shigella boydii & - & - & - & - & - & 42.0 \\
\hline Sh. dysenteriae & 8.0 & - & 16.0 & 8.0 & - & 38.0 \\
\hline Vibrio mimicus & 10.0 & 8.0 & 10.0 & - & - & 37.0 \\
\hline V. parahemolyticus & 12.0 & - & 10.0 & - & - & 37.0 \\
\hline
\end{tabular}




\section{Conclusion}

It is clearly evident from the above findings that the leaves of $M$. koenigii have significant free radical scavenging, cytotoxic and membrane stabilizing properties. The plant also exhibited mild to moderate thrombolytic potential. On the other hand, the bark of $A$. cordifolia demonstrated potent free radical scavenging, cytotoxic, membrane stabilizing and antimicrobial properties. The plants also exhibited mild thrombolytic potential. Leaves of $M$. koenigii are used for inflammation while the bark of $A$. cordifolia is used in the treatment of cancer, infections, inflammations etc. Our findings justify the traditional uses of these two plant species. Therefore, both the plants are good candidates for further chemical investigations to isolate the active constituents.

\section{References}

Adamu, H.M., Abayeh, O.J., Agho, M.O., Abdullahi, A.L., Uba, A., Dukku, H.U. and Wufem, B.M. 2004. An ethnobotanical survey of Bauchi state herbal plants and their antimicrobial activity. J. Ethnopharmacol. 99, 1-4.

Bakar, N.H.A., Sukari, M.A., Rahmani, M., Sharif, A.M., Khalid, K., and Yusuf, U.K. 2007. Chemical constituents from stem barks and roots of Murraya koenigii (Rutaceae). The Malaysian journal of analytical sciences. 11, 173-176.

Bauer, A.W., Kirby, W.M.M., Sheriss, J.C. and Turck, M. 1966. Antibiotic susceptibility testing by standardised single method. Am. J. Clin. Pathol. 45, 493-496.

Brand-Williams, W., Cuvelier, M.E. and Berset, C. 1995. Use of free radical method to evaluate antioxidant activity. Lebensm. Wiss. Technol. 28, 25-30.

Chowdhury, J.A., Islam, M.S., Asifuzzaman, Sk. and Islam, M.K. 2009. Antibacterial and cytotoxic activity screening of leaf extracts of Vitex negundo (Fam: Verbenaceae). J. Pharm. Sci. Res. 1, 103-108.
Chowdhury, J.U., Bhuiyan, M.N.I., and Yusuf, M. 2008. Chemical components of the leaf essential oils of Murraya koenigii (L.) Spreng and Murraya paniculata (L.) Jack. A Journal of the Bangladesh Pharmaceutical Society (BDPS). 3, 59-63.

Cragg, G.M., Newman, D.J. and Snader, K.M. 1997. Natural products in drug discovery and development. J. Nat. Prod. 60, 52- 60 .

Handral, H.K., Pandith, A., and Shruthi, S.D. 2012. A review on Murraya Koenigii: multipotential medicinal plant. Asian $J$. Pharm. Clin. Res. 5, 5-14.

Harbertson, J. and Spayd, S. 2006. Measuring phenolics in the winery. Am. J. Enol. Vitic. 57, 280-288.

Kaisar, M.A., Rahman, M.S., Rahman, M.Z., Hasan, C.M. and Rashid, M.A. 2011. A review on phytochemicals from some medicinal plants of Bangladesh. J. Phar. Nutri. Sci. 1, 8795.

Meyer, B.N., Ferringni, N.R., Puam, J.E., Lacobsen, L.B., Nichols, D.E. and McLaughlin, J.L. 1982. Brine shrimp: a convenient general bioassay for active constituents. Planta Med. 45, 31-32.

Omale, J. and Okafor, P.N. 2008. Comparative antioxidant capacity, membrane stabilization, polyphenols composition and cytotoxicity of the leaf and stem of Cissus multistriata. Afr. J. Biotechnol. 7, 3129-3133.

Prasad, S., Kashyap, R.S., Deopujari, J.Y., Purohit, H.J., Taori, G.M. and Daginawala, H.F. 2007. Effect of Fagonia arabica (Dhamasa) on in vitro thrombolysis, BMC Complement. Alternat. Med. 7, 7-36.

Rios, J.L. and Recio, M.C. 2005. Medicinal plants and antimicrobial activity. J. Ethnopharmacol. 100, 80-84.

Rokade, Y.R. and Pawar, D.S.P. 2013. A comprehensive review on Adina cordifolia. Int. J. Pharm. Sci. Rev. Res., 2, 13-16.

Van Wagenen, B.C., Larsen, R., Cardellina, J.H., Randazzo, D., Lidert, Z.C. and Swithenbank, C. 1993. Ulosantoin, a potent insecticide from the sponge Ulosa ruetzleri. J. Org. Chem. 58, 335-337. 